\title{
Prevalence and socioeconomic
} \section{associations of asthma and allergic rhinitis in nothern Africa}

\author{
V. Georgy*, H.I. Fahim\#", M. El Gaafary" and S. Walters*
}

ABSTRACT: The aims of the current study were to ascertain the prevalence of asthma and allergic rhinoconjunctivitis symptoms in Cairo, Egypt (nothern Africa), and to elucidate the socioeconomic factors associated with symptom prevalence and severity.

A translated and adapted version of the International Study of Asthma and Allergies in Childhood (ISAAC) questionnaire was distributed to a sample of 2,645 11-15-yr-olds in state and fee-paying schools in Cairo.

The overall prevalences of wheeze ever, wheeze during the last year and physician-diagnosed asthma were $26.5 \%$ (697 out of 2,631), $14.7 \%$ (379 out of 2,570) and $9.4 \%$ (246 out of 2,609), respectively. The prevalence of rhinoconjunctivitis was 15.3\% (399 out of 2,616). Asthma symptoms were independently associated with attendance at a state school, parental asthma, age, history of rhinitis and owning a pet cat. Rhinoconjunctivitis was independently associated with attendance at a state school, father's education, parental history of asthma, asthma symptoms and owning a pet cat. In spite of a higher prevalence of severe asthma symptoms in state schools prevalence of physician diagnosis of asthma was the same in both school types, suggesting inequalities in access to healthcare.

In conclusion, the prevalence of physician-diagnosed asthma in Cairo was $9.4 \%$, while the prevalence of rhinoconjunctivitis was $\mathbf{1 5 . 3 \%}$. There is a higher prevalence and increased severity of asthma symptoms in children of lower socioeconomic groups, as defined by state school attendance in Cairo.

KEYWORDS: Allergic rhinitis, asthma epidemiology, Cairo, population health, socioeconomic, wheeze

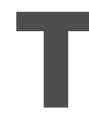
he prevalence of asthma and allergic rhinoconjunctivitis is high in western countries, and has been rising throughout the late 20th century. However, relatively little is known about the prevalence of allergic disorders in children in North Africa and the Middle East, and even less is known about the relative importance of socioeconomic factors in its aetiology in these countries, when compared to Europe, the USA and Australia.

Comparisons between the International Study of Asthma and Allergies in Childhood (ISAAC) prevalence results and the results of another international study, the European Community Respiratory Health Survey, have shown that although there are some differences in the absolute prevalence levels, there is good agreement of patterns between countries [1]. There are several hypotheses in the literature on the aetiology of asthma, many of which have been investigated in phases 2 and 3 of the ISAAC study [2]

The role of socioeconomic factors in the aetiology of asthma is not simple. The "hygiene hypothand cleanliness have reduced the chance for cross-infection in childhood and increased the risk of atopic sensitisation [3].

Although "poor" and "richer" children living in urban environments may be equally less exposed to faeco-oral pathogens than in the past, poorer children may still have a higher exposure to many risk factors facilitating severe asthma and wheezing. Such risk factors may include airborne viruses, smoke, indoor dampness, cockroaches and poor access to healthcare $[4,5]$.

It has consistently been found that people from low socioeconomic backgrounds tend to have a higher prevalence of severe asthma symptoms, esis" suggests that higher standards of hygiene

\section{AFFILIATIONS}

*Dept of Public Health and Epidemiology, University of Birmingham, Birmingham, UK

\#Faculty of Medicine, Ain Shams University, Cairo, Egypt.

\section{CORRESPONDENCE}

S. Walters

Dept of Public Health and

Epidemiology

Public Health Building

University of Birmingham

Birmingham

B15 2TT

UK

Fax: 441214147878

E-mail: s.walters@bham.ac.uk

Received:

August 012005

Accepted after revision:

May 232006 
even if the overall prevalence is no different to the rest of the population [5-7].

There have been very few studies of the epidemiology of asthma and allergic rhinitis in Egypt (nothern Africa). Egypt has been classified as a middle-income country by the World Bank, but there is a substantial amount of poverty and adult illiteracy is high $[8,9]$.

There is an urgent need to obtain more data on allergies and asthma from middle-income countries as the economic transition period may have dramatic effects on health, which could be affected by policy change.

The aims of this study are to determine the prevalence of asthma and allergic rhinoconjunctivitis in schoolchildren in Cairo, Egypt and to investigate the role of socioeconomic status on prevalence of asthma and allergic rhinoconjunctivitis.

\section{MATERIALS AND METHODS Study subjects}

The study population was taken from among 11-15-yr-old children in the first and second years of preparatory secondary school in the El Nozha area of Cairo. These schools comprise state schools, experimental language schools and private schools. Experimental language schools are fee-paying government schools and are classified with private schools in the analysis.

The El Nozha area education office provided a list of the local schools and gave written permission for the research to take place. Two sampling frames were created, one with state-run and another with private schools. A selection of schools was made from each frame until enough pupils were enrolled. Two experimental schools $(n=487)$, three private schools $(n=622)$ and three state schools $(n=1536)$ were included. One of the schools initially approached refused to take part in the study and so another school from the same sampling frame was chosen.

From an estimated school roll of 20,000, and underlying prevalence of asthma at 10\%, 2,144 participants were required in order to have $80 \%$ power to estimate prevalence of asthma to within $1.2 \%$ of the true value with $95 \%$ confidence.

In the absence of a formal research ethics mechanism covering schools in Cairo, the South Birmingham Research Ethics Committee was approached and gave notional permission for the study to be carried out. Permission from school head teachers was obtained. Information letters and consent forms were sent out to parents of the children a few days before the study questionnaire was administered. Fifty four (1.8\%) of the children in the study sample were withdrawn from the study by their parents.

\section{Study design}

An adapted version of the ISAAC questionnaire was used to measure symptom prevalence. The independent variable was the school type. Questionnaire delivery was controlled. Use of the ISAAC video was not within the resources available.

\section{Apparatus}

The study used an adapted ISAAC questionnaire comprising four sections: demographic information, breathing problems, nose problems and home environment.

\section{Development of study instrument}

The study questionnaire was developed using questions from the ISAAC phase 1 questionnaire [10]. Questions were asked about symptoms of asthma and allergic rhinitis as well as the home environment. In addition, some questions on socioeconomic status were added and piloted.

The questionnaire was translated into Arabic by an independent translator. Then the translation was revised by H.I. Fahim and M. El Gaafary. Phrases that were difficult for children to understand were changed and if there was no suitable word for them a verbal explanation was added as part of the study guidelines. The questionnaire was back-translated by a second independent translator.

A total of 56 children were involved in the piloting. These were recruited from Sunday school classes in the region. The final pilot was a class from a school in the sampling frame. As a result of the pilot, weaknesses in questions and confusing formatting were identified and corrected. Language problems were also noted and a standardised verbal explanation, given by two of the authors (V. Georgy and M. El Gaafary), was added to the study guidelines. This was standardised as far as possible using a protocol including the main points and phrases to be used.

Data collection took place between February and April 2003. Each school was visited twice. The first visit was to obtain the head teacher's permission and to distribute consent letters. On the second visit, the questionnaires were filled in by the children. This was under the supervision of trained field workers who followed a study protocol.

\section{Analysis}

A code was added to each questionnaire for school, year and class, and each was given a questionnaire ID.

Bivariate analysis was performed on all potential risk factors for asthma, allergic rhinitis and severity of asthma using the Chi-squared test. All variables that were significantly associated with symptoms were entered into a multiple logistic regression analysis model to assess factors independently associated with the following outcomes: wheeze in the last 12 months; severe asthma symptoms; nose problems in the last 12 months; and allergic rhinoconjunctivitis (nose problems in the last 12 months plus itchy watery eyes). Severe asthma was defined as having one or more of the following: wheeze that awakens the subject more than once a week; wheeze that hinders ability to talk; or wheeze that limits daily activity to a great extent. Allergic rhinoconjunctivitis was defined as the presence of itchy, watery eyes associated with nose symptoms.

\section{RESULTS}

A total of 3,002 children aged 11-15 yrs were eligible to receive a questionnaire. From these, 2,645 (88.1\%) completed questionnaires were received. Of the missing subjects, 303 were absent on the day of data collection and 54 children were withdrawn by their parents from the study or handed in "spoiled questionnaires". Thirty-one questionnaires were excluded as subjects were outside the study age range.

\section{Demographic characteristics of responders}

Of the respondents, $50.1 \%(1,325)$ were male and $49.8 \%(1,316)$ were female. Other demographic characteristics are shown in table 1. 
To make the best use of the data, all available responses were used in the analysis, so the total number of respondents may vary between analyses of individual risk factors.

\section{Prevalence of symptoms}

Overall, the prevalences of wheeze ever, wheeze during the last year and physician-diagnosed asthma were $26.5 \%$ (697 out of 2,631$), 14.7 \%$ (379 out of 2,570) and $9.4 \%$ (246 out of 2,609$)$, respectively.

The overall prevalence of allergic rhinitis nose symptoms, allergic rhinoconjuntivitis and physician diagnosis of allergic rhinitis was $40.0 \%(1,055 / 2,637), 15.3 \%(399 / 2,616)$ and $10.8 \%$ $(282 / 2,621)$.

\section{Socioeconomic status}

The following characteristics were used to define socioeconomic status: attendance at a fee-paying school versus a free state school; level of education of father; and level of education of mother. Information was also collected on occupation, but this was incomplete and not used in analysis.

\section{Bivariate analysis}

Table 2 shows that children from state schools had a higher prevalence of all symptoms than those in fee-paying schools. State-school children had a higher past-year wheezing prevalence than children in fee-paying schools (18.8 and 9.1\%, respectively) and more exercise-induced wheeze (35.6 and $18.6 \%$, respectively). There was a high prevalence of nocturnal cough in both groups, but it was also higher in state-school children (54.2 versus $30.9 \%)$. Allergic rhinitis was more prevalent in state schools than in fee-paying schools $(44.7$ versus $33.5 \%$ ) and the same was true for rhinoconjunctivitis (21.1 versus $7.2 \%$ ). However, there was no difference in the prevalence of physician diagnosis of asthma or allergic rhinitis between the two groups.

Symptoms were also more prevalent in those children whose mother or father had not received university-level education.

\section{Severity of symptoms}

Children from state schools had a higher prevalence of severe asthma symptoms than those in fee-paying schools (13.1 versus $4.9 \% ; \mathrm{p}<0.001)$. The proportion of individuals with severe asthma symptoms but without a diagnosis of asthma is higher in state schools than in fee-paying schools $(63.3 \%$ of those with severe symptoms versus $29.6 \% ; \mathrm{p}<0.001)$. Severity is also higher in children whose parents have not had university-level education.

\section{Wheeze during the last year}

All the variables that were significantly associated with symptoms in the bivariate analysis were included in the multiple logistic regression models. The results are shown in table 2. The number of siblings a respondent had was not included as it was not significant in the bivariate analysis.

Factors strongly associated $(\mathrm{p}<0.001)$ with having wheeze during the last year were: a parent with asthma; nose symptoms during the last year; rhinoconjunctivitis; and physician-diagnosed rhinitis (table 2). Adjusted odds ratios (OR; 95\% confidence intervals (CI)) of comorbidities were, respectively, 1.87 (1.33-2.64), 1.86 (1.38-2.52), 2.45 (1.78-3.38)

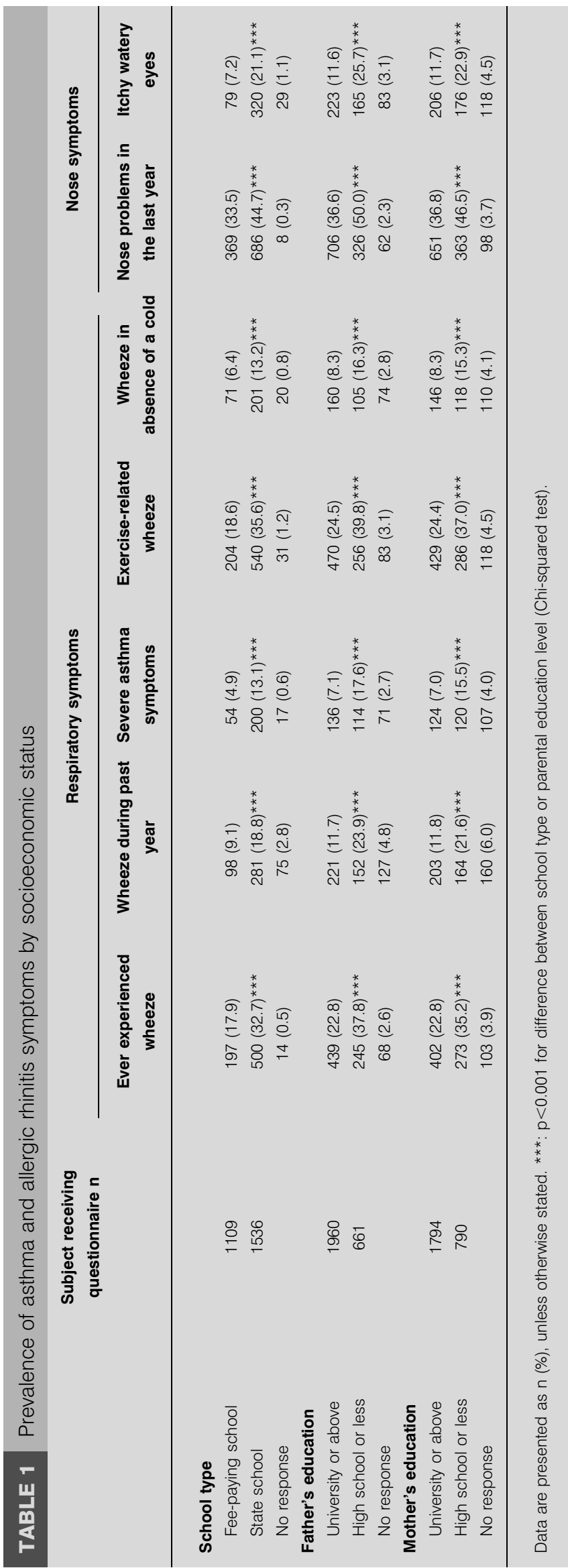




\begin{tabular}{|c|c|c|c|c|c|}
\hline \multirow[t]{2}{*}{ TABLE 2} & \multicolumn{5}{|c|}{$\begin{array}{l}\text { Multivariate analysis for prevalence of nose symptoms, rhinoconjunctivitis, wheeze in the last } 12 \text { months and severe } \\
\text { asthma symptoms }\end{array}$} \\
\hline & & Nose symptoms in last year & Rhinoconjunctivitis & Wheeze in last year & Severe asthma symptoms \\
\hline \multicolumn{2}{|c|}{ State school } & $1.36^{* \star}(1.11-1.68)$ & $2.69^{* \star *}(1.94-3.73)$ & $1.68^{\star \star}(1.23-2.31)$ & $1.99^{* \star}(1.34-2.95)$ \\
\hline \multicolumn{2}{|c|}{ Father's education" ${ }^{\#}$} & $1.42^{*}(1.04-1.95)$ & $1.61 *(1.07-2.43)$ & $1.30(0.86-1.96)$ & $1.37(0.86-2.24)$ \\
\hline \multicolumn{2}{|c|}{ Mother's education ${ }^{\#}$} & $0.77(0.57-1.04)$ & $0.75(0.49-1.13)$ & $1.09(0.72-1.64)$ & $1.10(0.68-1.79)$ \\
\hline \multicolumn{2}{|c|}{ Age $1+$} & $1.22(0.95-1.58)$ & & $1.86^{\star *}(1.21-2.85)$ & $1.72 *(1.03-2.87)$ \\
\hline \multicolumn{2}{|l|}{ Age $2+$} & $1.23(0.94-1.60)$ & & $2.25^{\star \star \star}(1.45-3.49)$ & $2.10^{* *}(1.24-3.55)$ \\
\hline \multicolumn{2}{|l|}{ Age $3+$} & $1.37(0.92-2.03)$ & & $2.06 *(1.16-3.67)$ & $2.41 *(1.24-4.68)$ \\
\hline \multicolumn{2}{|l|}{ Age $4+^{\circ}$} & $3.39(1.12-10.19)$ & & $3.04 *(1.00-9.19)$ & $3.45^{*}(1.05-11.37)$ \\
\hline \multicolumn{2}{|l|}{ Pet cat } & $1.46^{*}(1.03-2.03)$ & $1.20(0.77-1.89)$ & $1.61 *(1.02-2.52)$ & $1.35(0.79-2.29)$ \\
\hline \multicolumn{2}{|l|}{ Any pets } & $1.05(0.85-1.30)$ & $1.38^{*}(1.03-1.86)$ & $1.00(0.73-1.36)$ & $1.01(0.70-1.46)$ \\
\hline
\end{tabular}

Data are presented as adjusted odds ratio (95\% confidence interval). ${ }^{*}$ : father's and mother's education compare education at university level or above with education below university level; " : ages $12,13,14$ and 15 yrs, respectively, compared with all other ages. ${ }^{* \star *}: p<0.001 ;{ }^{* *}: p<0.01 ;{ }^{*}: p<0.05$.

and 2.26 (1.63-3.13). Age and school type were less strongly associated with wheezing during the last year. There was also an association $(p<0.05)$ between having a cat in the house and wheeze.

\section{Severe asthma symptoms}

Factors strongly associated $(p<0.001)$ with having severe asthma symptoms were: a parent with asthma; rhinoconjunctivitis; and physician-diagnosed rhinitis (table 2). Adjusted OR $(95 \% \mathrm{CI})$ of the latter two variables were 2.48 (1.71-3.58) and 3.01 (2.10-4.32). Other significant associations with severe asthma symptoms were nose symptoms during the last year $(\mathrm{p}<0.01$, adjusted OR (95\% CI) 1.79 (1.23-2.59)) and age $(\mathrm{p}<0.05)$. Having a cat in the house was not associated with severe asthma symptoms.

\section{Nose symptoms}

Wheezing during the last year was strongly $(p<0.001)$ associated with nose symptoms (adjusted OR (95\% CI) 2.09 (1.41-3.11)). Having someone who smokes in the house was also strongly associated with nose symptoms $(\mathrm{p}<0.01)$. There was an association between nose symptoms and school type $(\mathrm{p}<0.01)$ and between rhinoconjunctivitis and school type $(\mathrm{p}<0.001)$, with children from state schools having a higher risk of nose symptoms and rhinoconjunctivitis. There were also significant $(\mathrm{p}<0.05)$ associations between nose symptoms and father's education, parental history of asthma, age, having a cat in the house and physician-diagnosed asthma.

\section{Rhinoconjunctivitis}

Wheezing during the last year and having a smoker in the house were associated with rhinoconjunctivitis $(\mathrm{p}<0.001$, adjusted OR (95\% CI) 2.61 (1.63-4.17); and $\mathrm{p}<0.01$ respectively). Severe asthma symptoms were also associated with rhinoconjunctivitis ( $\mathrm{p}<0.05$, adjusted OR (95\% CI) 1.72 (1.03$2.89)$ ). Children from state schools were 2.7 times as likely to have rhinoconjunctivitis as those from fee-paying schools.
Although having a cat was not a significant risk factor for rhinoconjunctivitis, having any pets was. The number of siblings was included in the multivariate analysis but was not found to be significant.

\section{DISCUSSION}

This study has established the prevalence of asthma symptoms, nose symptoms and symptoms of allergic rhinoconjunctivitis in this relatively affluent area of Cairo. It has also shown a definite association between asthma and allergic rhinitis symptoms and social class. People from lower-income families (as defined by school type) were 1.5 times as likely to have had wheeze during the last year and twice as likely to have had severe symptoms as people from a higher socioeconomic background. In addition, children from state schools were 2.5 times as likely to have rhinoconjunctivitis as their colleagues in private schools.

\section{Prevalence of symptoms}

The international literature shows that asthma prevalence differs between countries, with higher rates in more affluent countries [11-13]. Table 3 illustrates some of the variation between countries in the Middle East, the current study and the UK.

The prevalence of rhinoconjunctivitis, recent wheeze and physician-diagnosed asthma in all of the Middle Eastern countries is lower than in the UK. The prevalence of physician-diagnosed asthma in the current study in Cairo is at the lower end of the spectrum for the region.

\section{The influence of socioeconomic factors}

This study demonstrated a significant association between socioeconomic status and symptoms, with both higher prevalence and severity found in the lower socioeconomic group.

Within Israel, comparisons between Arab and Jewish children found that Jewish children have double the prevalence rate for 
TABLE 3 Prevalence of rhinoconjunctivitis, recent wheeze and physician-diagnosed asthma in the Middle East and the UK

\begin{tabular}{|c|c|c|c|}
\hline Location [Ref.] & Rhinoconjunctivitis & Wheeze in the last 12 months & Physician-diagnosed asthma \\
\hline Cairo & 15.3 & 14.7 & 9.4 \\
\hline UK $[10,14]$ & 18.2 & 33.3 & 20.9 \\
\hline \multirow[t]{2}{*}{ Israel $[15,16]$} & 15.8 & 20.1 (Jewish) & 7.8 (Jewish) \\
\hline & & 10.1 (Arab) & 4.9 (Arab) \\
\hline Palestine ${ }^{\#}[17]$ & & 8.8 & 9.4 \\
\hline \multirow{2}{*}{ Saudi Arabia [19] } & 13.9 (urban) & 13.2 (urban) & 15.1(urban) \\
\hline & 8.0 (rural) & 6.4 (rural) & 5.0 (rural) \\
\hline Kuwait [20] & & 16.1 & 16.8 \\
\hline
\end{tabular}

Data are presented as \%. *: refugee camps.

current wheeze of Arab children (20.7 versus 10.1\%) [16]. This is in an environment where the Arab community tend to be poorer and have worse living conditions than the Jewish community [16]. However, within Palestinian refugee camps, the prevalence of physician-diagnosed asthma was similar to that found in Cairo [21]. Conversely, the same study found a higher prevalence of wheezing in the last 12 months and diagnosed asthma in the westernised district of Ramallah than in North Gaza [21]. This picture would seem to suggest that within communities, socioeconomic status is associated with asthma symptoms, but between communities with different lifestyles, asthma symptom prevalence is higher in affluent areas. This latter picture is consistent with the hygiene hypothesis and the picture of asthma prevalence in Europe $[13,22,23]$.

In Saudi Arabia [19], although the symptom prevalence is lower than that found in Cairo, the prevalence of physiciandiagnosed asthma is higher. This may be due to variations in healthcare between the two countries.

In a study of 4,300 7-15-yr-old males in Saudi Arabia, lower monthly family income was associated with having asthma [24]. A study in Norway also found that markers of low socioeconomic status were associated with asthma in young children [4]. These findings are consistent with results of asthma studies in Chicago (IL, USA) that have found that asthma is more prevalent and severe in inner cities than in the rest of the country [25].

Alternative hypotheses need to be sought regarding environmental exposures that might explain the complex relationship between socioeconomic status and prevalence of asthma and allergic rhinitis in different countries, communities and cultures. Of particular interest is the consistent association between cockroach allergen and asthma symptoms [26, 27].

It has been shown that high levels of cockroach allergen seem to be associated with lower socioeconomic status [28]. In addition, the association between cockroach allergen in the family room and repeated wheezing during childhood has been shown to be significant even after adjusting for socioeconomic factors [25].
The environment in Egypt encourages cockroaches to thrive and it is possible that this is a significant contributor to asthma prevalence in lower socioeconomic groups.

\section{Severity of asthma symptoms}

This study also showed a difference in symptom severity between socioeconomic groups. Not only were the rates of severe asthma symptoms higher in the lower socioeconomic group, but of children with severe asthma symptoms, a higher proportion from state schools than from fee-paying schools did not have a physician diagnosis of asthma (63 versus $30 \%$ ).

This is an important finding. It suggests that children from poorer families do not have access to healthcare and thus do not receive a diagnosis of asthma, nor do they receive appropriate treatment for it. This agrees with the UK findings of DURAN-TAULERIA and RONA [5] that children from inner cities whose father's social class was low and who lived in a poor area had a higher prevalence of persistent wheeze than children in the rest of the sample. Similar findings of higher levels of severe asthma among lower socioeconomic groups have been described elsewhere [6, 7].

It seems likely that the discrepant findings of this study, higher prevalence and greater severity of symptoms in poorer children, but with no difference in prevalence of diagnosed asthma, are at least in part due to discrepancies in access to healthcare.

\section{Limitations of the study}

Translation of the ISAAC questionnaire into Arabic is difficult. Although there is a medical word for wheezing in the Arabic language, it is not widely understood by the age group of the study. As a result, two researchers gave a verbal description of wheezing in every classroom. A study protocol was used to maximise consistency.

The proportion of the total child population attending school in Cairo is not known with accuracy. As $42 \%$ of the Egyptian population is illiterate [9], it is likely that a substantial minority of younger children do not attend school. However, local informants suggested that the rate of nonschool attendance was likely to be lower in the city of Cairo than in other parts of 
Egypt, so it is difficult to estimate the effect that this might have on the current prevalence results.

\section{Conclusion}

In conclusion, among 11-15-yr-old schoolchildren in Cairo, the overall prevalence of wheezing in the last year was $14.7 \%$ and of physician-diagnosed asthma was $9.4 \%$. This study clearly shows that allergic rhinoconjunctivitis and asthma symptoms are much more prevalent among those from poorer backgrounds. Children attending state schools also showed a higher prevalence of severe asthma symptoms but were much less likely to have a physician diagnosis of asthma, which points to discrepancies in access to healthcare. Asthma is relatively common, and probably underdiagnosed and undertreated, particularly among children from less wealthy families in Cairo.

In this middle-income country, economic growth and the associated improvement in housing and sanitation has resulted in fewer childhood gastrointestinal infections. The loss of this protective effect against atopy in the city may have contributed to an increased prevalence of atopic symptoms. This evidence suggests a worldwide expansion in the allergy epidemic.

\section{ACKNOWLEDGEMENTS}

The authors would like to thank all the children who filled in the questionnaires and all the people who assisted with the field work, especially S. Rizkallah. They would also like to thank T. Marshall for his support in all ethical matters.

\section{REFERENCES}

1 Pearce N, Sunyer J, Cheng S, et al. Comparison of asthma prevalence in the ISAAC and the ECRHS. Eur Respir J 2000; 16: 420-426.

2 ISAAC Steering committee home page. http://isaac.auckland.ac.nz. Date last updated: February 2, 2005. Date last accessed: June 12, 2005.

3 Strachan DP. Hay fever, hygiene and household size. BMJ 1989; 299: 1259-1260.

4 Lindbaek M, Wefring KW, Grangard EH, Ovsthus K. Socioeconomical conditions as risk factors for bronchial asthma in children aged 4-5 yrs. Eur Respir J 2003; 21: 105-108.

5 Duran-Tauleria E, Rona RJ. Geographical and socioeconomic variation in the prevalence of asthma symptoms in English and Scottish children. Thorax 1999; 54: 476-481.

6 Littlejohns P, Macdonald LD. The relationship between severe asthma and social class. Respir Med 1993; 87: 139-143.

7 Mielck A, Reitmeir P, Wjst M. Severity of childhood asthma by socioeconomic status. Int J Epidemiol 1996; 25: 388-393.

8 The World Bank. Egypt overview. http://web.worldbank. org / WBSITE /EXTERNAL/COUNTRIES/MENAEXT / EGYPTEXTN/0,menuPK:287164 pagePK:141132 piPK: 141121 theSitePK:256307,00.html Date last updated: 2005. Date last accessed: June 12, 2005.

9 CIA The World Factbook - Egypt. http://www.cia.gov/ cia/publications/factbook/geos/eg.html Date last updated: June 2 2005. Date last accessed June 122005.
10 Austin JB, Kaur B, Anderson HR, et al. Hay fever, eczema and wheeze: a nationwide UK study (ISAAC, international study of asthma and allergies in childhood). Arch Dis Child 1999; 81: 225-230.

11 Bousquet J, van Cauwenberge P, Khaltaev N. Allergic rhinitis and its impact on asthma. J Allergy Clin Immunol 2001; 108: Suppl. 5, S147-S334.

12 The International Study of Asthma Allergies in Childhood (ISAAC) Steering Committee, Worldwide variation in prevalence of symptoms of asthma, allergic rhinoconjunctivitis, and atopic eczema: ISAAC. Lancet 1998; 351: $1225-1232$.

13 von Mutius E, Weiland SK, Fritzsch C, Duhme H, Keil U. Increasing prevalence of hay fever and atopy among children in Leipzig, East Germany. Lancet 1998; 351: 862-866.

14 Kaur B, Anderson HR, Austin J, et al. Prevalence of asthma symptoms, diagnosis and treatment in 12-14 year old children across Great Britain (international study of asthma and allergies in childhood, ISAAC UK). BMJ 1998; 316: 118-124.

15 Graif Y, Garty BZ, Livne I, Green MS, Shohat T. Prevalence and risk factors for allergic rhinitis and atopic eczema among schoolchildren in Israel: results from a national study. Ann Allergy Asthma Immunol 2004; 92: 245-249.

16 Shohat T, Green MS, Davidson Y, Livine I, Tamir R, Garty BZ. Differences in the prevalence of asthma and current wheeze between Jews and Arabs: results from a national survey of schoolchildren in Israel. Ann Allergy Asthma Immunol 2002; 89: 386-392.

17 El-Sharif N, Abdeen Z, Qasrawi R, Moens G, Nemery B. Asthma prevalence in children living in villages, cities and refugee camps in Palestine. Eur Respir J 2002; 19: 1026-1034.

18 Al-Riyami BM, Al-Rawas OA, Al-Riyami AA, Jasim LG, Mohammed AJ. A relatively high prevalence and severity of asthma, allergic rhinitis and atopic eczema in schoolchildren in the Sultanate of Oman. Respirology 2003; 8: 69-76.

19 Hijazi N, Abalkhail B, Seaton A. Asthma and respiratory symptoms in urban and rural Saudi Arabia. Eur Respir J 1998; 12: 41-44.

20 Behbehani NA, Abal A, Syabbalo NC, Abd Azeem A, Shareef E, Al-Momen J. Prevalence of asthma, allergic rhinitis, and eczema in 13- to 14-year-old children in Kuwait: an ISAAC study. International Study of Asthma and Allergies in Childhood. Ann Allergy Asthma Immunol 2000; 85: 58-63.

21 El Sharif NA, Nemery B, Barghuthy F, Mortaja S, Qasrawi R, Abdeen Z. Geographical variations of asthma and asthma symptoms among schoolchildren aged 5 to 8 years and 12 to 15 years in Palestine: the International Study of Asthma and Allergies in Childhood (ISAAC). Ann Allergy Asthma Immunol 2003; 90: 63-71.

22 Heinreich J, Popescu MA, Wjst M, Goldstein IF, Wichmann HE. Atopy in children and parental social class. Am J Public Health 1998; 88: 1319-1324.

23 von Mutius E, Fritzsch C, Weiland SK, Roll G, Magnussen H. Prevalence of asthma and allergic disorders 
among children in united Germany: a descriptive comparison. BMJ 1992; 305: 1395-1399.

24 Cook DG, Strachan DP. Effects of maternal and paternal smoking on children's respiratory health. In: WHO, Tobacco free Initiative, eds. International Consultation on Environmental Tobacco Smoke (ETS) and child health. Geneva, World Health Organisation, 1999; pp. 31-59.

25 Grant EN, Daugherty SR, Moy JN, Nelson SG, Piorkowski JM, Weiss KB. Prevalence and burden of illness for asthma and related symptoms among kindergarteners in Chicago public schools. Ann Allergy Asthma Immunol 1999; 83: 113-120.
26 Kang B, Sulit N. A comparative study of prevalence of skin hypersensitivity to cockroach and house dust antigens. Ann Allergy 1978; 41: 333-336.

27 Rosenstreich DL, Eggleston P, Kattan M, et al. The role of cockroach allergy and exposure to cockroach allergen in causing morbidity among inner-city children with asthma. N Engl J Med 1997; 336: 1356-1363.

28 Leaderer BP, Belanger K, Triche E, et al. Dust mite, cockroach, cat and dog allergen concentrations in homes of asthmatic children in the northeastern United States: impact of socioeconomic factors and population density. Environ Health Perspect 2002; 110: 419-425. 